\title{
A description of karyotype of the giant liver fluke Fascioloides magna (Trematoda, Platyhelminthes) and a review of Fasciolidae cytogenetics
}

\author{
M. REBLÁNOVÁ ${ }^{1 *}$, M. ŠPAKULOVÁ ${ }^{1}$, M. OROSOVÁ ${ }^{1,2}$, E. BAZSALOVICSOVÁ ${ }^{1}$, D. RAJSKÝ ${ }^{3}$
}

\author{
${ }^{1}$ Parasitological Institute of the Slovak Academy of Sciences, Hlinkova 3, 040 01, Košice, Slovak Republic, \\ E-mail: reblan@saske.sk; ${ }^{2}$ Institute of Parasitology, Biology Centre ASCR, Branišovská 31, 37005 České Budějovice, \\ Czech Republic; ${ }^{3}$ Faculty of Forestry, Technical University in Zvolen, T.G. Masaryka 20, 06053 Zvolen, Slovakia
}

\begin{abstract}
Summary
The study describes a karyotype of a common parasite of cervids, the giant liver fluke, Fascioloides magna (Trematoda, Platyhelminthes). The chromosome set of F. magna comprises 11 pairs of chromosomes, all classified as subtelocentric except for the submeta-metacentric pair No. 8 and the submetacentric pair No. $10(2 \mathrm{n}=22, \mathrm{n}=1 \mathrm{sm}+$ $1 \mathrm{sm}-\mathrm{m}+9 \mathrm{st})$. The first longest pair is $4.65 \mu \mathrm{m}$ long and the length decreases continuously to the $1.92 \mu \mathrm{m}$ length of the last pair No. 11. No distinct secondary constriction has been observed in mitotic preparations. Fluorescent DAPIstaining reveals distinct heterochromatin bands on all 11 chromosome pairs in the centromeric regions; another DAPI-positive bands are localized at the end of the long arms of chromosomes No. 5 and the last less distinct signals appear interstitially on the long arms of the pair No. 6 . Synchronous meiotic divisions of 8-spermatocyte groups have been observed during spermatogenesis, similarly with a development of spermatocytes in other trematodes. In the first two stages of heterotypic spermatocyte division, 11 bivalents $(n=11)$ are regularly observed, confirming the diploid number of 22 elements. Furthermore, the present analysis summarises and discusses available cytogenetic data on Fasciolidae flukes suitable for future studies on taxonomy or phylogenetic interrelationships within the family.
\end{abstract}

Keywords: fasciolid flukes; chromosome; fluorescent staining; heterochromatin

\section{Introduction}

Fascioloides magna (Bassi, 1875) (Fasciolidae) is a veterinary important liver fluke of a variety of wild and domestic ruminants, namely cervids, cattle, sheep, goats and a series of other hosts. It is generally accepted that the trematode has its original territory in the North America (Pybus, 2001), and was introduced to Europe along with its hosts, wapiti deer, in the $19^{\text {th }}$ century (Bassi, 1875). Till now, the reports on occurrence of $F$. magna in Europe were documented from German-Polish border, Czech Republic, Spain, Slovakia, Hungary, Austria, and Croatia appeared (for review see Novobilský et al., 2007). Fascioloides magna is a single-species genus and differs from other fasciolid liver flukes by conspicuously larger body size being $80-100 \mathrm{~mm}$ long, $20-35 \mathrm{~mm}$ wide and $2.0-4.5 \mathrm{~mm}$ thick, as well as by other specific morphological traits (Špakulová et al., 2003). Its life cycle includes the aquatic snails of the family Lymnaeidae as intermediate hosts within which several generations of larvae develop by asexual multiplication. This intramolluscan period results in releasing of free-swimming cercariae which encapsulate on water or marsh plants and wait out to be grazed by final ruminant host (Erhardová-Kotrlá, 1971). The number and shape of chromosomes represent important characteristics of biological species. The first raw information on the chromosome number in $F$. magna $(2 \mathrm{n}=$ 22) was published by Špakulová et al. (2003) but detailed characteristics of a chromosomal structure has not been published yet.

In this paper, we present the original description of chromosome set of the giant liver fluke assessed on the basis of mitotic divisions of spermatogonial cells isolated from fluke testes. A course of spermatogenesis, as inferred from meiotic divisions of spermatocytes, was studied as well. Besides, so far available cytogenetic data on Fasciolidae flukes are summarized and cytogenetic markers are discussed as valuable tool in future taxonomic and phylogenetic studies of the family.

\section{Materials and methods}

Parasites

Twelve living flukes, processed immediately after dissection of seven red deer (Cervus elaphus) livers, were used 
for cytogenetic study. Red deer were hunted in Danube basin near the village Bodíky (southern Slovakia, Dunajská Streda district) through the years 2006-2008; one deer was shot near Beroun, central Bohemia, Czech Republic, in November 2008.

\section{Chromosome preparations}

Immediately after dissection, whole living flukes were placed into saline solution with $0.025 \%$ colchicine for $1-4$ hours by room temperature. Small portions of tissue, situated in the middle third of the body and containing parts of tubular testes, were dissected and processed according to the spreading method described by Fuková et al. (2005) with some modifications. Shortly, the small pieces of testes were incubated in a hypotonic solution of $75 \mathrm{mM} \mathrm{KCl}$ for $15-30 \mathrm{~min}$, fixed in freshly prepared Carnoy (ethanol:chloroform:acetic acid 6:3:1) for 15 - 30 min. After fixation, samples were transferred into a drop of $60 \%$ acetic acid on a slide and torn into fine pieces using tungsten needles. Then the slide with a drop of cell suspension was placed on a heating plate at $45{ }^{\circ} \mathrm{C}$ and fluid was slowly drawn along the slide until it evaporated. Preparations were screened in a phase contrast microscope, the best of them were dehydrated in ethanol series $(70,80$ and $100 \%, 1$ min each) and kept at $-20{ }^{\circ} \mathrm{C}$ until further use.

\section{Karyological analysis}

Slides were stained in $5 \%$ solution of Giemsa-Romanowski dye (Merck, New Jersay, USA) in buffer phosphate solution ( $\mathrm{pH}$ 6.8) for $15-30 \mathrm{~min}$ and flushed with flowing water.

Another preparations were stained with the DNA binding dye, $0.5 \mu \mathrm{g} / \mathrm{ml}$ DAPI (4',6-diamino-2-phenylidole; SigmaAldrich, St. Louis, USA) and mounted in antifade based on DABCO (Sigma-Aldrich). Preparations were observed and photographed in the combined light and fluorescent microscope Olympus BX 51 with digital camera DP70. Digital images were processed with Adobe Photoshop, version 7.0. Karyological data (absolute and relative lengths and centromeric index) were calculated from 10 best spermatogonial spreads out of 69 evaluated mitoses. The classifica- a
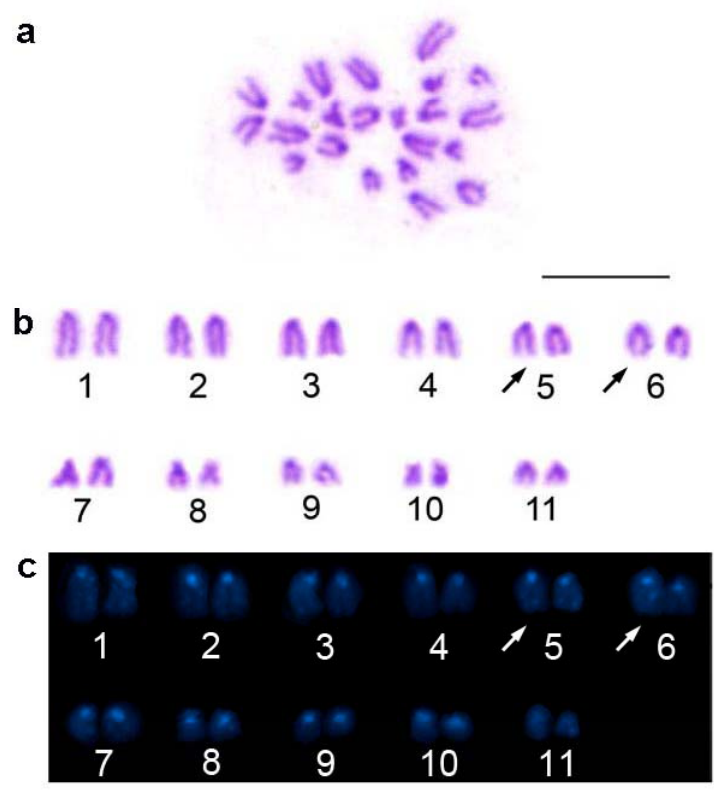

Fig. 1. Mitotic chromosomes of Fascioloides magna. a - spread mitotic metaphase stained by Giemsa; $b$ - karyotype derived from the cell shown in Fig. 1a; c - another mitotic set stained by DAPI. Scale bar indicates $10 \mu \mathrm{m}$; arrows indicate chromosome pair with extracentromeric heterochromatin blocks.

tion of chromosomes followed the nomenclature of Levan et al. (1964).

\section{Results}

The diploid chromosome number of $F$. magna is $2 \mathrm{n}=22$ (Fig. 1, Tab. 1). Out of 69 observed mitotic spermatogonial cells, $15(21.7 \%)$ were aneuploid; the random lack of one or two chromosomes can be explained as methodological problem caused by the spreading technique. In first meiotic division of spermatocytes, a haploid set of $n=11$ bivalents was regularly observed which is in agreement with the diploid number. All 11 chromosome pairs were relatively similar in their length and morphology. The length

Table1. Measurements (means \pm SD) and classification of chromosomes of Fascioloides magna

\begin{tabular}{ccccc}
\hline $\begin{array}{c}\text { Chromosome } \\
\text { number }\end{array}$ & $\begin{array}{c}\text { Absolute } \\
\text { length }(\boldsymbol{\mu m})\end{array}$ & $\begin{array}{c}\text { Relative } \\
\text { length }(\boldsymbol{\%})\end{array}$ & $\begin{array}{c}\text { Centromeric } \\
\text { index }\end{array}$ & Classification \\
\hline 1 & $4.65 \pm 0.41$ & $13.25 \pm 0.96$ & $16.46 \pm 3.60$ & st \\
2 & $4.24 \pm 0.41$ & $12.06 \pm 0.37$ & $17.98 \pm 3.13$ & st \\
3 & $4.03 \pm 0.36$ & $11.32 \pm 0.37$ & $18.34 \pm 2.64$ & st \\
4 & $3.70 \pm 0.12$ & $10.52 \pm 0.31$ & $20.47 \pm 4.49$ & st \\
5 & $3.42 \pm 0.34$ & $9.70 \pm 0.47$ & $21.00 \pm 3.97$ & st \\
6 & $3.12 \pm 0.35$ & $8.82 \pm 0.37$ & $20.90 \pm 3.52$ & st \\
7 & $2.77 \pm 0.43$ & $7.98 \pm 0.59$ & $21.98 \pm 3.59$ & st \\
8 & $2.69 \pm 0.41$ & $7.63 \pm 0.54$ & $37.09 \pm 2.73$ & sm-m \\
9 & $2.36 \pm 0.24$ & $6.79 \pm 0.57$ & $24.16 \pm 5.97$ & st \\
10 & $2.27 \pm 0.31$ & $6.47 \pm 0.63$ & $28.94 \pm 2.70$ & sm \\
11 & $1.92 \pm 0.33$ & $5.43 \pm 0.55$ & $24.24 \pm 2.62$ & st \\
\hline Note; st - subtelocentric, sm-m - submeta-metacentric, sm- submetacentric chromosome pair
\end{tabular}




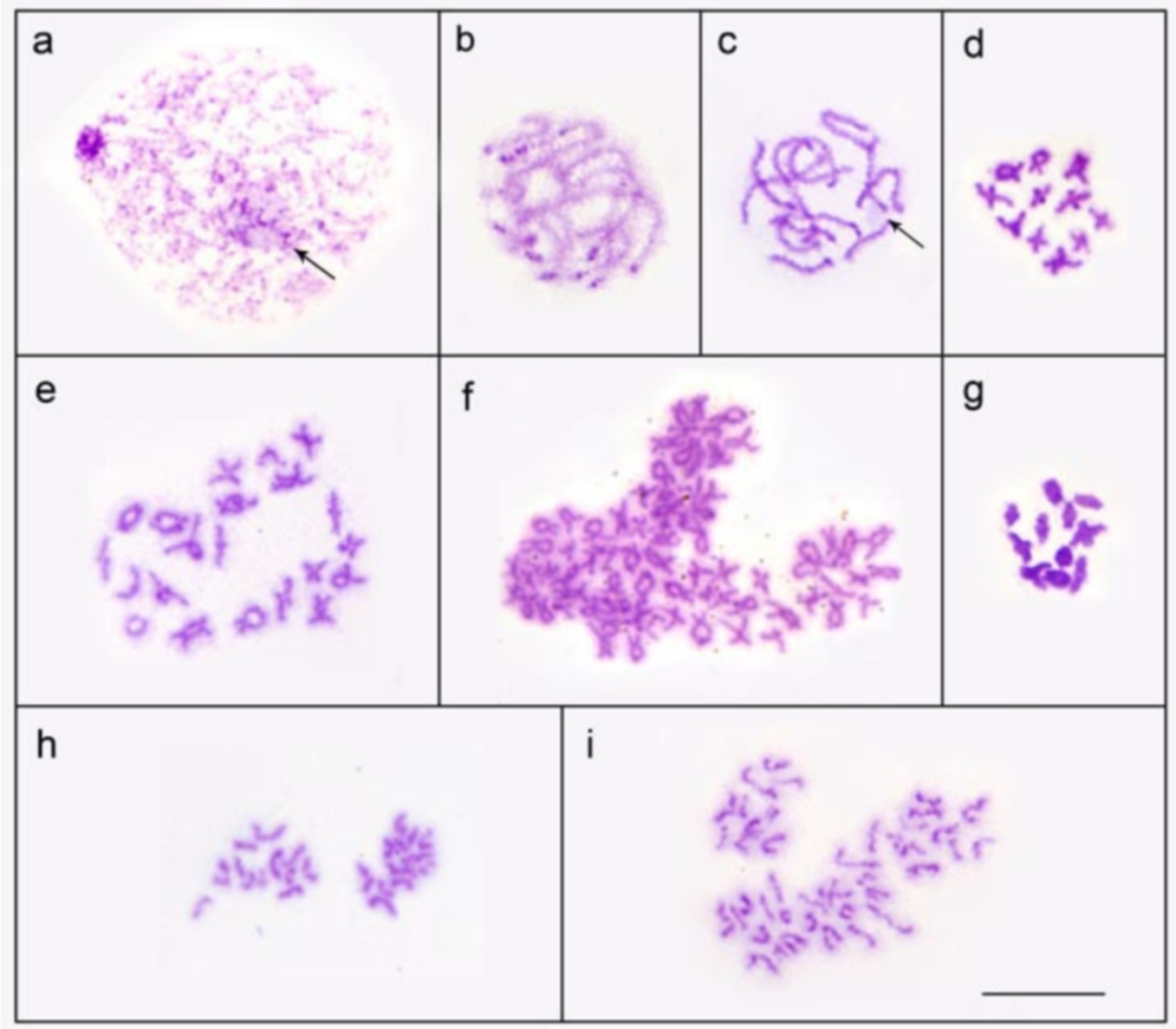

Fig. 2. Meiotic chromosomes of Fascioloides magna stained by Giemsa. a - leptotene; b, c - pachytene; d, e, f-diakinesis, one cell (d), two cells (e), eight cells (f); g - metaphase I; h - metaphase II; i - anaphase II, four cells. Scale bar indicates $10 \mu \mathrm{m}$; arrow indicates nucleolus.

descended continuously with small differences between the neighbouring pairs (Tab. 1) and the mean total length of the haploid genome (TCL) reached $35.17 \mu \mathrm{m}$. The largest pair was $4.65 \mu \mathrm{m}$ long occupying $13.25 \%$ of TCL, the smallest one measured $1.92 \mu \mathrm{m}$ which represented $5.43 \%$ of TCL. Regarding morphology, nearly all chromosome pairs were classified as subtelocentric; the only exceptions were the submeta-metacentric pair No. 8 and submetacentric pair No. 10 (Tab. 1). The karyotype formula is $2 n=22, n=$ $1 \mathrm{sm}+1 \mathrm{sm}-\mathrm{m}+9 \mathrm{st}$. No distinct secondary constriction was observed in mitotic preparations (Fig. 1a - c). Fluorescent DAPI-staining revealed distinct heterochromatin bands on all 11 chromosome pairs in their centromeric regions (Fig. 1c). Another DAPI-positive band was localized at the end of the long arm of the pair No. 5 and a last less distinct signal appeared interstitially on the long arm of the pair No. 6 (see arrows in Fig. 1b, c).

In meiotically dividing spermatocytes (Fig. $2 \mathrm{a}-\mathrm{c}$ ), a single nucleolus was observed from leptotene (Fig. 2a) to pachytene (Fig. 2c) stages. Pachytene nuclei showed clumps of 11 bivalents with darkly stained pericentromeric heterochromatin blocks (Fig. 2 b, c). A synchronous meiotic division of up to 8-spermatocyte groups was observed; during diakinesis, one to maximum eight cells were often found in slides (Fig. 2d, e, f). Clusters of diverse number of synchronously dividing secondary spermatocytes were seen, as well (Fig. 2h, i).

\section{Discussion}

The family Fasciolidae comprises six genera (Protofasciola, Fasciolopsis, Parafasciolopsis, Fascioloides, Fasciola, Teniufasciola) with nine species occurring in various artiodactyls, primarily in wild and domestic ruminants, but also in hogs and pigs, elephants and hippos (Jones, 2005). Out of them, Fasciola hepatica L., 1758, F. gigantica Cobbold, 1869 and Fasciolopsis buski (Lankester, 1857) may parasitize also humans and have high medical importance (Lotfy \& Hillier, 2003; Mas-Coma et al., 2005; Dorko et al., 2009). Therefore, these flukes have been studied most intensively for a variety of biological features including chromosomes (for review see Baršiené, 1993). In addition to medically and veterinary important fasciolid species, a karyotype of Parafasciolopsis fasciolaemorpha Ejsmont, 1932, the parasite of elk and cervids, was also described (Baršiené, 1990). The survey on cytogenetic data of fasciolid species, except for the papers dealing exclusively with ploidy, is provided in Table 2. 


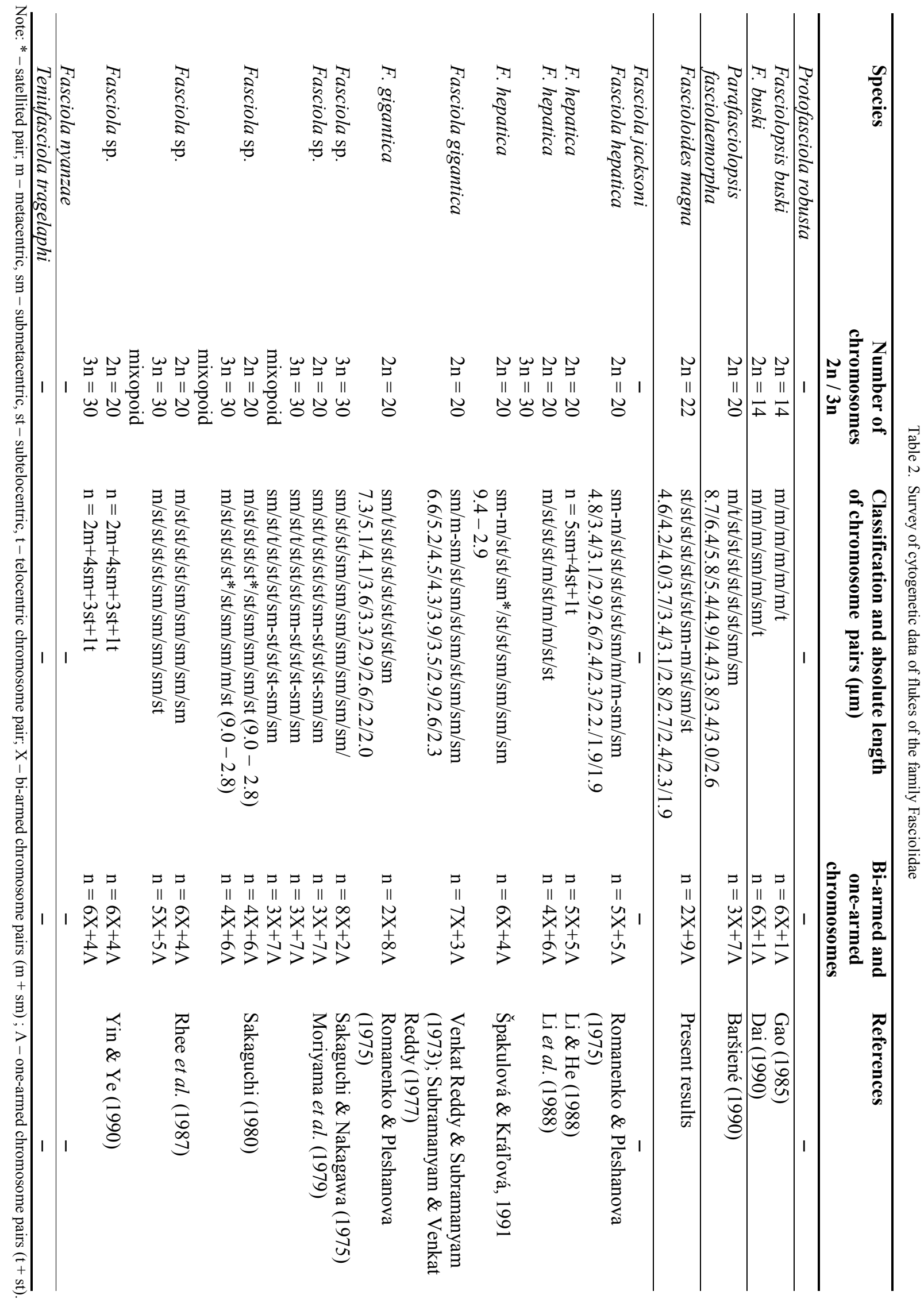


The fasciolids are aligned according to their hypothetical evolutionary origin (Lotfy et al., 2008; Prasad et al., 2008). The karyotype of $F$. magna, described here in detail for the first time, differs from chromosome sets of all other fasciolids by higher diploid number $2 \mathrm{n}=22$. Namely, $F$. hepatica and $F$. gigantica have $2 \mathrm{n}=20$; triploid forms, reported often in both species and in Fasciola sp., have $3 \mathrm{n}=$ 30 (Sanderson, 1953; Terasaki et al., 2000; Itagaki et al., 2009 and references therein). The chromosome number $2 \mathrm{n}$ $=20$ is characteristic also for $P$. fascioaemorpha (Baršiené, 1990). Fasciolopsis buski differs from all fasciolids by low number of chromosomes, having $2 \mathrm{n}=14$ (Lo, 1969; Gao, 1985; Dai et al., 1990). Except of chromosome number, the karyotype of $F$. magna varies from other fasciolid species chiefly by morphology of the first chromosome pair. It is of medium length and clearly subtelocentric in the giant liver fluke but longer and metacentric or submetacentric in all other species (see Tab. 2).

A comparison of ratio of telocentric and subtelocentric (i.e. one-armed) and metacentric and submetacentric (bi-armed) chromosome pairs in karyotypes of individual fasciolid species (Table 2, column 4) reveals that one-armed chromosomes predominate in $P$. fasciolaemorpha and $F$. magna, both belonging to evolutionary basal or intermediate fasciolid species, as ascertained by Lotfy et al. (2008) by molecular phylogenetic study. This fits well with a hypothesis that less advanced species of a specific group usually possess non-symmetric karyotype with higher number of one-armed chromosomes and lower proportion of bi-armed elements (White, 1973). On the other hand, the karyotype of another, presumably basal, fasciolid species F. buski (Lotfy et al., 2008; Prasad et al., 2008) apparently represents an exception having only 14 chromosome pairs, all but one being metacentric (Gao, 1985; Dai, 1990). It seems that karyotype evolution of this Asian parasite accelerated rapidly after it had derived from the common ancestor and acquired human and domesticated pig hosts.

Regarding multiple records on karyotypes of $F$. hepatica, $F$. gigantica and Fasciola sp., the cytogenetic data are often contradictory. While $F$. hepatica seems to have balanced incidence of one- and bi-armed chromosome types (Romanenko \& Pleshanova, 1975; Li et al., 1988; Špakulová \& Králová, 1991), the data referred to $F$. gigantica and Fasciola sp. are much more discrepant (see Table 2). In general, genetic variation within the Fasciola spp. throughout the world is outstanding. In many Asian countries from Iran and India as well as in Pacific islands Taiwan, the Philippines and Hawaii, $F$. hepatica, $F$. gigantica and Fasciola sp. exhibit not only diploid, but also triploid populations and even mixoploid (2n/3n) specimens (e.g. Moriyama et al., 1979; Sakaguchi, 1980; Terasaki et al., 1998, 2000; Itagaki et al., 2009; Srimuzipo et al., 2000; Ichikawa \& Itagaki, 2010). Additionally, triploid $F$. hepatica has been found in Britain and Ireland (Fletcher et al., 2004). Recent molecular studies have suggested that the origin of Asian triploids may be hybridization between $F$. hepatica and $F$. gigantica (Itagaki \& Tsutsumi, 1998; Agatsuma et al., 2000; Lin et al., 2007; Itagaki et al., 2009; Peng et al., 2009). Moreover, Terasaki et al. (2000), Fletcher et al. (2004) and Dreyfuss \& Rondelaud (2008) suggest that triploidy in Fasciola spp. probably arises repeatedly and occasionally in various regions by a variety of mechanisms and facultative gynogenesis is thus widespread in Fasciola. Local populations could be outbreeding and diverse, or clonal with few genotypes present (Fletcher et al., 2004). A rather broad genetic diversity among geographically distinct Fasciola populations was also discussed by Semyenova et al. (2006) and Dreyfuss \& Rondelaud (2008). It seems likely that divergent intraspecific lineages might differ also in their karyotypes (see discrepancies in Table 2). In this respect, it would be worthwhile to supplement future molecular studies of Fasciola spp. with thorough determination of chromosome characteristics and vice versa.

Except of chromosome number and shape, additional chromosomal characteristics like distribution of heterochromatin can help us to clarify phylogenetic relationships. As usual in hermaphroditic platyhelminthes (e.g. Mutafova et al., 1986; Špakulová \& Králová, 1991; Orosová et al., 2010 ), the karyotype of $F$. magna possess rather small amount of heterochromatin distributed mainly near the centromeres. Interestingly, slight interstitial bands were found in two middle-sized chromosome pairs. However, their specification requires further analysis with a use of molecular cytogenetic methods (e.g. fluorescent in situ hybridization, FISH) in higher number of Fasciolidae species.

Development of spermatocytes of $F$. magna corresponds with that of other hermaphroditic digenean trematodes (Gresson, 1965). It is known that in the testis of a fluke, primary, secondary and tertiary spermatogonia are present and that their mitotic divisions are mostly synchronized. Hence, we have often found groups up to eight primary spermatocytes in various stages of meiosis (mainly in diakinesis). During the second meiotic division, 16 secondary spermatocytes give a group of 32 haploid spermatids. We have not observed any deviations from this standard (see Fig. 2). The process of degradation of nucleolus during meiotic prophase (between pachytene and metaphase I) in $F$. magna also confirms related data in other Platyhelminthes (e.g. Orosová et al., 2010)

In spite of the fact that our present knowledge on cytogenetics of Fasciolidae flukes is not sufficient to draw general lines of chromosome evolution within the group, the present analysis provides new valuable markers suitable for future comparative evaluation of respective taxonomic or phylogenetic questions.

\section{Acknowledgements}

We acknowledge Dr. Martin Kašný (Faculty of Science, Charles University, Prague, Czech Republic) for a kind providing us with a Czech material of F. magna. The work was supported by grants of the Slovak Research and Development Agency No. LPP-0126-07 and APVV-51- 
062205, the National Science Foundation, USA (PBI award Nos. 0818696 and 0818823), the Grant Agency of the Czech Republic (No. 524/08/0885), research projects of the Institute of Parasitology BC ASCR (Z60220578, LC 522 ), and it was realized within a frame of Centre of Excellence for Parasitology (Code ITMS: 26220120022) based on the support of the Operational Programme "Research \& Development" funded from the European Regional Development Fund (rate 0.2).

\section{References}

Agatsuma, T., Arakawa, Y., Iwagami, M., Honzako, Y., Cahyaningsih, U., Kang, S-Y., Hong, S-J. (2000): Molecular evidence of natural hybridization between Fasciola hepatica and F. gigantica. Parasitol. Int., 49(3): 231 - 238. DOI: 10.1016/S1383-5769(00)00051-9

BARŠIENÉ, J. (1990): Chromosome sets of trematodes Parafasciolopsis fasciolaemorpha (Ejsmont, 1932) and Cathemasia hians (Rudolphi, 1809) Looss, 1899. Helminthologia, 27(3): 145 - 152

BARŠIENÉ, J. (1993): The karyotypes of trematodes. Vilnius, Lithuania: Academia, 370 pp. (In Russian)

BASSI, R. (1875): Sulla cachessia ittero-vermicosa, o marciaia dei Cervi, causata dal Distomum magnum. Med. Vet.Torino, 4: 497 - 515

DAI, X. (1990): Karyotype analysis of Fasciolopsis buski. J. Chongquin Med. Univ., 4: 11. DOI: cnki: ISSN:0253-36 26.0.1990-04-004

Dorko E., BArAnovÁ, Z., Dubinský, P., PISTL, J. (2009): Bacterial, viral, parasitic and mycotic zoonoses: Viral and parasitic zoonoses. Equilibria, 367 pp. ISBN 978-80-892 84-32-0. (In Slovak)

Dreyfuss , G., Rondelaud, D. (2008): Biodiversity of flukes. Parasite, 15(3): $282-285$

ERHARDOVÁ-KotRLÁ, B. (1971). The occurrence of Fascioloides magna (Bassi, 1875) in Czechoslovakia. Prague, Czech Republic, Academia, 155 pp.

Fletcher, H. L., Hoey, E. M., OrR, E. M., Trudgett, A., FAIRWEATHER, I., RoBINSON, M. V. (2004): The occurrence and significance of triploidy in the liver fluke, Fasciola hepatica. Parasitology, 128(1): 69 - 72. DOI: 10.10 17/S003118200300427X

FukovÁ, I., NGuYen, P., MAREC, F. (2005): Codling moth cytogenetics: karyotype, chromosomal location of rDNA, and molecular differentiation of sex chromosomes. Genome, 48(6): 1083 - 1092. DOI: 10.1139/G05-063

GAO L. (1985): Observation of meiosis of Fasciolopsis buski. Hereditas (Beijing), 7 (2): 22 - 23. DOI: cnki: ISSN: 0253-9772.0.1985-02-009

GRESSON, R. A. R. (1965): Spermatogenesis in the hermaphroditic Digenea (Trematoda). Parasitology, 55: 117 125. DOI: $10.1017 / \mathrm{S} 0031182000068426$

ICHIKAWA, M., ITAGAKI, T. (2010): Discrimination of the ITS1 types of Fasciola spp. based on a PCR-RFLP method. Parasitol. Res., 106(3): 757 - 761. DOI: 10.1007/ s00436-010-1724-2

Itagaki, T., Tsutsumi, K. (1998): Triploid form of Fas- ciola in Japan: genetic relationships between Fasciola hepatica and Fasciola gigantica determined by ITS-2 sequence of nuclear rDNA. Int. J. Parasitol. 28(5): 777 781. DOI: 10.1016/S0020-7519(98)00037-X

Itagaki, T., SaKaguchi, K., Terasaki, K., Sasaki, O., Yoshihara, S., VAN DunG, T. (2009): Occurrence of spermic diploid and aspermic triploid forms of Fasciola in Vietnam and their molecular characterization based on nuclear and mitochondrial DNA. Parasitol. Int., 58(1): 81 - 85. DOI: 10.1016/j.parint.2008.11.003

JONES, A. 2005. Family Fasciolidae Railliet, 1895. In: Jones, A., Bray, R. A., GiBson, D. I. (Eds) Keys to the Trematoda. Volume 2. London, UK: CABI Publishing and The Natural History Museum, pp. $79-86$.

LEVAN, A., FredGA, K., SANDBERG, A. (1964): Nomenclature for centromere position on chromosomes. Hereditas 52(2): 201 - 220. DOI: 10.1111/j.1601-5223.1964.tb019 53.x

LI, J., HE, L. (1988): Analysis of meiosis and karyotype of Fasciola hepatica. J. First Millit. Med. Univ., 1: 11. DOI: cnki: ISSN: 1000-2588.0.1988-01-020

LI, G. Q., Jin, J. S., WANG, P. Y. (1988): A study on the chromosomes of Fasciola hepatica. Chin. J. Veter. Sci. Technol., 6: $11-16$

Lin, R.Q., Dong, S. J., Nie, K., WAnG, C. R., Song, H. Q., LI, A. X., Huang, W. Y., Zhu, X. Q. (2007): Sequence analysis of the first internal transcribed spacer of rDNA supports the existence of the intermediate Fasciola between $F$. hepatica and $F$. gigantica in mainland China. Parasitol. Res., 101(3): 813 - 817. DOI: 10.1007/s00436007-0512-0

LO, C. T. (1969): Chromosomes of Fasciolopsis buski. Trematoda. Fasciolidae. Bull. Inst. Zool. Acad. Sinica, 8(1): $1-5$

LOTFy, W. M., Hillier, G. V. (2003): Fasciola species in Egypt. Exp. Pathol. Parasitol. 6 (11): 9 - 22

Lotfy, W. M., Brant, S. V., DeJong, R. J., Le, T. H., Demiaszkiewicz, A., Rajapakse, R. P. V. J., Perera, V. B. V. P., LAURSEN, J. R., LOKER, E. S. (2008): Evolutionary origins, diversification and biogeography of liver flukes (Digenea, Fasciolidae). Am. J. Trop. Med. Hyg., 79(2): $248-255$

MAs-Coma, S., Bargues, M. D., VAlero, M. A. (2005): Fascioliasis and other plant-borne trematode zoonoses. In Int. J. Parasitol., 35(11-12): 1255 - 1278. DOI: 10.1016/ j.ijpara.2005.07.010

Moriyama, N., Tsuji, M., SETo, T. (1979): Three karyotypes and their phenotypes of Japanese liver flukes (Fasciola sp.). Jpn. J. Parasitol. 28(1): 23 - 33. (In Japanese with English summary).

Mutafova, T., Tsocheva, N., Polyakova-Krsteva, O., KRSTEV, L. (1986): Effect of diethylnitrosamin on the chromosome structure of rats infected with Fasciola hepatica and on that of the liver fluke. Khelmithologiya (Sofia), 22: $42-50$

NovobilskÝ, A., HoráČKOVÁ, E., HiRTOVÁ, L., ModrÝ, D., KoudelA, B. (2007): The giant liver fluke Fascioloides magna (Bassi, 1875) in cervids in the Czech Republic and 
potential of its spreading to Germany. Parasitol. Res., 100(3): 549 - 553. DOI: 10.1007/s00436-006-0299-4

Orosová, M., Marec, F., Oros, M., XI, B. W., Scholz, T. (2010): A chromosome study and localization of $18 \mathrm{~S}$ rDNA in Khawia saurogobii (Cestoda: Cryophyllidea). Parasitol. Res., 106(3): 587 - 593. DOI: 10.1007/s00436009-1702-8

Peng, M., IChinomiYa, M., Ohtori, M., IchiKawa, M., SHIBAHARA, T., ITAGAKI, T. (2009): Molecular characterization of Fasciola hepatica, Fasciola gigantica, and aspermic Fasciola sp. in China based on nuclear and mitochondrial DNA. Parasitol. Res., 105(3): 809 - 815. DOI: 10.1007/s00436-009-1459-0

Prasad, P. K., Tandon, V., Biswal, D. K., Goswami, L. M., ChAtTerJe, A. (2008): Molecular identification of the Indian liver fluke, Fasciola (Trematoda: Fasciolidae) based on the ribosomal internal transcribed spacer regions. Parasitol. Res., 103(6): 1247 - 1255. DOI: 10.1007/s00436008-1121-2

Pybus, M. J. (2001): Liver flukes. In SAmuEL, W. M., Pybus, M. J., Kocan, A. A. (Eds) Parasitic diseases of wild mammals, Ames, Iowa, Iowa State Press, pp. 121 - 149

RHEE, J. K., EUN, G. S., LE, S. B. (1987): Karyotype of Fasciola sp. obtained from Korean cattle. Korean J. Parasitol., 25(1): 37 - 44. DOI: 10.3347/kjp.1987.25.1.37 (In Korean, abstract in English)

Romanenko, L. N., Pleshanova, N. M. (1975): Chromosome sets of Fasciola hepatica and Fasciola gigantica. Trudy VIGIS (Teoreticheskie problemy veterinarnoy gel'mintologii), 22: $137-142$

SANDERSON, A. R. (1953): Maturation and probable gynogenesis in the liver fluke, Fasciola hepatica L. Nature, 172(4368): 110 - 112. DOI: 10.1038/172110a0

SAKAGUCHI, Y. (1980): Karyotype and gametogenesis of the common liver fluke, Fasciola sp., in Japan. Jpn. J. Parasitol., 29: 507 - 513

SaKaguchi, Y., NaKagawa, C. (1975): A note on the chromosome of the common liver fluke (Faciola sp.) from Japan. Chromosome Inform. Surv., 19: 25 - 26

Semyenova, S. K., Morozova, E. V., Chrisanfova, G. G., Gorokhov, V. V., Arkhipov, I. A., Moskvin, A. S.,
Movsessyan, S. O., RYSKOV, A. P. (2006): Genetic differentiation in eastern European and western Asian populations of the liver fluke, Fasciola hepatica, as revealed by mitochondrial nad 1 and cox 1 genes. J. Parasitol., 92(3): 525 - 530. DOI: 10.1645/GE-673R.1

Srimuzipo, P., Komalamisra, C., Choochote, W., Jipakdi, A., VAnichthanaKom, P., Keha, P., RiYOng, D., Sukontason, K., Komalamisra, N., Sukontason, K., TIPPAWANGKOSOL, P. (2000): Comparative morphometry, morphology of egg and adult surface topography under light and scanning electron microscopies, and metaphase karyotype among three size-races of Fasciola gigantica in Thailand. Southeast Asian J. Trop. Med. Publ. Health, 31(2): $366-373$

Subramanyam, S., VenKat Reddy P. (1977): The role of chromosomes in the taxonomy of some digenetic trematodes. The Nucleus, 20(1 and 2): $128-138$

ŠPAKUlovÁ, M., KrÁlovÁ, I. (1991): Chromosomes of Fasciola hepatica (Digenea: Fasciolidae) from western Bohemia (CSFR). Helminthologia, 28(4): 197 - 200

ŠPAKUlOVÁ, M., RAJSKÝ, D., SOKOL, J., VODŇANSKÝ, M. (2003): Giant liver fluke (Fascioloides magna), an important liver parasite of ruminants. Bratislava, Slovak Republic, PaRPRESS, $61 \mathrm{pp}$.

TERASAKI, K., MoriYAmA-GondA, N., NodA, Y. (1998): Abnormal spermatogenesis in the common liver fluke (Fasciola sp.) from Japan and Korea. J. Vet. Med. Sci. 60(12): 1305 - 1309. DOI: 10.1292/jvms.60.1305

Terasaki, K., Noda, Y., Shibahara, T., ItAgaki, T. (2000): Morphological comparisons and hypotheses on the origin of polyploids in parthenogenetic Fasciola sp. J. Parasitol., 86(4): 724 - 729. DOI: 10.1645/00223395(2000)086[0724:MCAHOT]2.0.CO;2

Venkat Reddy, P., Subramanyam, S. (1973): Chromosome studies in the liver fluke, Fasciola gigantica Cobbold, 1856, from Andhra Pradesh. Curr. Sci., 42: 288 - 291

YIN, H. Z., YE, B.Y. (1990): Studies on the karyotypes of Fasciola spp. Chin. J. Parasitol. Parasitic Dis. 8(2): $124-126$ White, M. J. D. (1973): Animal Cytology and Evolution. New York: Cambridge University Press. 961 pp. 